\title{
BYLAAG
}

\section{DIE CHEMIESE BEDRYF EN STANDAARDISASIE*}

\section{Inleiding}

Dit is inderdaad reeds ou nuus dat $u$ 'n Departement van Industriële Chemie gestig het. Dit was egter 'n stap van soveel fundamentele betekenis vir die nywerheidstoekoms van ons land dat $\mathbf{u}$ my dit moet vergun om weer eens daarna te verwys en $u$ nie alleen van harte geluk te wens met hierdie stap nie, maar ook die opregte wens uit te spreek dat hierdie Departement baie sterk sal ontwikkel en 'n groot en positiewe bydrae sal lewer tot die opleiding veral van bedryfsleiers, maar ook van navorsingsleiers vir die chemiese bedryf.

Hoe belangrik is hierdie chemiese bedryf wat tans, soos die legendariese reus, besig is om te ontwaak en wat ons probeer help?

In ronde syfers is ons sekondêre nywerheidswese se bydrae tot die totale volksinkomste ongeveer 25 persent in geldelike waarde verreweg die belangrikste enkel pilaar waarop die volkshuishouding rus.

Die chemiese bedryf lewer op sy beurt ongeveer 30 persent van die bydrae van die sekondêre vervaardigingsbedryf, en ek noem hierdie syfer om die relatiewe belangrikheid aan te dui van die chemiese bedryf wat $u$ deur $u$ Departement Industriële Chemie direk gaan bedien.

Ek keer later tot hierdie punt terug met enkele gegewens, maar u sal dadelik besef dat ons met 'n groot en belangrike bedryf te doen het wat in die jare wat voorlê net sal aanhou groei. Hierdie groei is onvermydelik omdat die chemiese bedryf ' $n$ basiese voorsiener of bydraer is tot alle aspekte van die menslike lewe, byvoorbeeld voedselvoorsiening, gesondheid, behuising, vervoer en kommunikasie.

Ek wil in die eerste plek enkele gedagtes oor die chemiese bedryf uitspreek en gegewens verstrek ten opsigte van die

\footnotetext{
* Inougurele rede soos opgestel deur wyle prof. dr. A. W. Lategan om gelewer te word met die aanvaarding van 'n ere-professoraat in Industriële Chemie aan die P.U. vir C.H.O. op 29 Oktober 1965. Prof. Lategan is egter op 23 Oktober 1965 oorlede.
} 
bedryf self, veral omdat dit een van ons jong bedrywe is waaroor daar nie genoeg geskryf en gepraat word nie en waarvan die relatiewe waarde nie oral ten volle besef word nie.

Ek sal my natuurlik bepaal by die bedryf soos dit in SuidAfrika opgekom en verstewig geraak het en by die rol wat dit in die ekonomie van ons land speel. In ander lande, veral die V.S.A. en Duitsland, is die chemiese bedryf relatief baie groter, baie langer gevestig en word dit baie meer algemeen erken as 'n onmisbare deel van die ekonomie.

\section{Histories}

Ek wil begin met 'n oorsig - uit die aard van die saak 'n baie beknopte oorsig - van die geskiedenis van die chemiese bedryf.

Net soos dit die geval is op alle ander vakgebiede, het die chemiese bedryf sy pioniers wie se name miskien slegs in 'n klein kringetjie bekend is, maar wat nietemin gehuldig moet word vir hulle ware baanbrekerswerk, wat eerstens tot baie groot ontwikkelings gelei het, en tweedens vir ons op elke gebied van die lewe in staat gestel het om die lewenspeil te kan handhaaf wat ons wel vandag geniet. Name soos Lavoisier, Priestley and Cavendish, almal beroemde en oorspronklike indiwiduele navorsers en die grondleggers van die moderne chemie, staan soos bakens langs die pad.

'n Mens kom ook baie ander name teë van mense wat as indiwidue gewerk het en die grondslae van die fundamentele chemiese bedryf gelê het. Veral Leblanc, Perkin, Kekulé, Von Baeyer, Solvay, Mond en Volta toring hier bo die ander uit.

Gedurende ons eeu het reuse soos Haber en Baekeland groot indiwiduele bydraes gemaak. Hulle name is aan alle chemici bekend, maar ek is seker dat ook baie van u dié name en ander sal herken deur prosesse en produkte wat vandag in algemene gebruik is en hulle name dra.

Maar veral gedurende die afgelope 50 jaar het die chemiese bedryf vinnig uitgebrei en soveel navorsing vereis, dat die tempo van ontwikkeling dermate versnel moes word; gevolglik kon die indiwiduele navorser of prosesontwikkelaar nie die pas volhou nie en het hierdie werk in die hande van spanne werkers oorgegaan.

Ons het dus vandag die verskynsel dat op die gebied van chemie en fisika, die enkeling selde op die voorgrond tree soos dit nog algemeen die geval is met byvoorbeeld die 
geesteswetenskappe. Instede daarvan word navorsing aan die universiteite of in nywerheidslaboratoriums onderneem, waar spanne werkers hulle kragte saamgooi om nuwe prosesse en produkte te ontwikkel. Die gevolg is dat ontwikkeling teen 'n steeds toenemende tempo plaasvind en dat die ontuikkelings in moderne chemiese tegnologie en verwante rigtings soos farmaseutika, biochemie, ens., werklik fantasties is.

\section{Opkoms van die chemiese bedryf in Suid-Afrika}

Oor die hele wêreld begin die nywerheidsbedrywigheid gewoonlik met die verwerking van primêre produkte. So ook in Suid-Afrika, en indien tuisnywerhede, soos seepmakery en kruieverwerking, buite rekening gelaat word, is die oudste chemiese bedryf in die Republiek dan ook ongetwyfeld die gisting van druiwesap om wyn te maak.

Dit was darem nie Bacchus nie, maar Vulcanus wat gesorg het vir die verdere ontwikkeling van die chemiese tegnologie: die eintlike begin van die georganiseerde chemiese bedryf het op die ontwikkeling van die mynbedryf gevolg, veral na die ontdekking van goud, wat die groot aanvraag na springstowwe geskep het.

Vir alle praktiese doeleindes begin die chemiese bedryf in Suid-Afrika in 1895, toe President Kruger „De Zuid-Afrikaansche Fabrieken voor Ontplofbare Stoffen, Bpk." te Modderfontein geopen het.

Terloops - hierdie beskeie begin het in die kort tydsbestek van sewentig jaar gelei tot die posisie waar Suid-Afrika vandag die twee grootste plofstoffabrieke in die wêrcld, een van die grootste ureumfabrieke in die wêreld, en die grootste kunsmisfabriek in die Suidelike Halfrond besit. 'n Ware kettingreaksie is deur hierdie beskeie begin ontketen ten opsigte van opleiding, navorsing, landbouproduksie, nywerheidsproduksie en mynbou.

Die Modderfonteinfabriek was 'n monopolie, en dit was onvermydelik dat mededinging uitgelok sou word en in 1903 word De Beers in die Kaap gestig, gevolg deur Kynochs in Natal in 1909, albei om in die eerste plek plofstowwe te vervaardig. Hierdie drie maatskappye het uiteindelik saamgesmelt en die teenswoordige African Explosives and Chemical Industries Ltd. gevorm, 'n maatskappy wat baie jare lank die toneel sou oorheers en vir Suid-Afrika 'n chemiese bedryf sou 
verseker wat buite verhouding tot sy algemene peil van nywerheidsontwikkeling was, maar in die eerste plek, toegespits was op die vervaardiging van springstowwe vir die land se snelontwikkelende mynbedryf.

Vóór die opkoms van die vervaardigende nywerheid, was eers die landboubedryf en later die mynbedryf die hoekstene van ons landsekonomie, en waar die mynbedryf met sy behoefte aan plofstowwe ons eerste ontwikkelingsperiode met die geboorte van die chemiese nywerheid 'n sewentigtal jare gelede tot stand gebring het, is die tweede fase van ons chemiese bedryf kort na die Eerste Wêreldoorlog as gevolg van die behoeftes aan 'n meer wetenskaplik-georiënteerde landboubedryf ingelui. By Umbogintwini is die surplus swawelsuur aangewend om Marokkaanse rotsfosfaat tot superfosfaat te verwerk. So het ons groot kunsmisnywerheid begin. Daar was later aanvraag na kalkswael, kopersulfaat, loodarsenaat, natriumarsenaat, magnesiumsulfaat en verskeie ander chemiese stowwe.

Gedurende die tydperk tussen die twee wêreldoorloë is die vervaardiging van 'n paar anorganiese chemikalieë onderneem waarvan kalsiumkarbied die belangrikste was, maar die volgende noemenswaardige ontwikkeling het eers in die vroeë dertigerjare plaasgevind met die vervaardiging by Modderfontein van sintetiese ammoniak wat gebruik word by die produksie van salpetersuur en ammoniumnitraat.

Gedurende dieselfde tydperk is YSKOR opgerig wat met die produkte van sy kooksinstallasie die begin van ons organiese chemiese bedryf ingelui het.

Die jare net vóór, en veral gedurende die Tweede Wêreldoorlog het die chemiese bedryf vinnig begin ontuikkel. Dié tydperk van versnelde tempo kan beskou word as die derde fase in die ontwikkeling van ons chemiese bedryf.

Gedurende dié tydperk is die fermentasie van stysel en suiker in Natal en die Transvaal onderneem en het dit tot die produksie van 'n hele reeks organiese chemikalieë gelei. Jare later sou hierdie bedryf snel uitgebou word om 'n veel groter reeks chemiese stowwe te ervaardig. Gedurende dieselfde tydperk is daar ook 'n begin gemaak met die elektrolise van sout, wat op sy beurt gelei het tot die vervaardiging van 'n hele reeks chemiese stowwe te vervaardig. Gedurende dieselfde tydders en bleikmiddels, maar later ook polivinielchloried. Dit, op sy beurt, het gelei tot interessante ontwikkelings in die bedryf 
en ook in die alledaagse lewe.

Ander belangrike en interessante ontwikkelings gedurende hierdie fase was SATMAR se kraakeenheid in die vervaardiging van motorbrandstof uit torbaniet, die herraffinering van smeerolie, die produksie van vitamien A-ryke lewertraan, visolie en gefraksioneerde visolies wat goeie substitute is vir lynolie vir verfvervaardiging van chroomsoute vir die looibedryf, en chroompigmente, harse en plastiseermiddels vir die snelont wikkelende verfvervaardigingsbedryf.

Die vierde en belangrikste fase in die ontwikkeling van die chemiese bedryf staan grootliks tot eer van die Staat en is ingelui met die stigting van SASOL in 1950.

Alhoewel die primêre doel die vervaardiging van motorbrandstof volgens die Fischer-Tropsch-sintese was, is uit die staanspoor besef dat hierdie bedryf eintlik die uitgangspunt van reuse-ontwikkelings in die hele organiese chemiese bedryf sou word.

Die vyftigerjare is ook gekenmerk deur uitbreidings in die bestaande anorganiese chemiese bedryf. Hier noem ek die groot uitbreiding in die vervaardiging van stikstof vir kunsmis, en die stigting van FOSFOR, ook deur die Staat, om rotsfosfaat te konsentreer - 'n onderneming wat die land byna selfversorgend gemaak het wat fosfatiese kunsmis betref.

Dit is interessant dat FOSKOR, wat as chemiese bedryf opgerig is, die voorloper van groot ontwikkelings in die mynbedryf geword het in teenstelling met African Explosives, wat as chemiese bedryf die uitvloeisel van Mynbedrywighede was. Die ontginning en veredeling van rotsfosfaat by FOSKOR het reeds tot die herwinning van koper gelei en sal hopelik later lei tot die heruinning van silwer, alumina en kaliumsoute.

Die jongste ontwikkeling in die chemiese bedryf is die vervaardiging van die grondstowwe vir kunsrubber - ' $n$ tipiese voorbeeld wat aandui hoe stewig die fondament vir 'n groot chemiese bedryf in Suid-Afrika gelê is.

Ons moet nou die huidige stand van die bedryf in die landsekonomie beskou.

Gedurende die afgelope 20 jaar het die sekondêre nywerhede vinniger gegroei as die landsekonomie as geheel, naamlik van 'n bruto-opbrengs van 1059 miljoen rand in 1948 tot 3125 miljoen rand in 1961: 'n Vermeerdering van 8.6 persent per jaar.

Salarisse en lone het met 170 persent van 250 miljoen rand 
tot 648 miljoen rand gestyg teen 'n gemiddelde jaarlikse koers van 7.9 persent.

Selfs teen hierdie agtergrond vertoon die chemiese nywerhede baie skouspelagtig. Bruto-opbrengs het met 282 persent gestyg van 89 miljoen rand tot 340 miljoen rand - 'n gemiddelde jaarlikse groeikoers van 10.9 persent, terwyl salarisse en lone met 373 persent gestyg het van 11 miljoen rand tot 52 miljoen rand - 'n koers van gemiddeld 12.7 persent per jaar.

Daar is geen aanduiding dat die groeikrag van die chemiese bedryf sal verslap nie, en sy toekoms kan as niks anders as rooskleurig beskryf word nie.

Professor Ligthelm het onlangs op uitstekende wyse 'n oorsig gegee van nuwe ondernemings wat gestig word en bestaande ondernemings wat uitgebrei $\mathrm{u}$ ord, en daaruit kan u self aflei dat die chemiese bedryf een van die mees dinamiese vertakkings in ons nywerheidswese is. Die huidige stand van die chemiese bedryf in Suid-Afrika moet nie net in terme van sy ekonomiese betekenis vir die volkshuishouding gesien word nie, maar ook as prestige-onderneming wat nywerheidsvolwassenheid aandui. Ondernemings soos FOSKOR, en veral SASOL, het vir Suid-Afrika groot roem in die buiteland verwerf.

Ek hoop dat ek daarin geslaag het om aan $u$ en almal wat daarby belang het, by herhaling enigsins ' $n$ aanduiding te gee van die belangrikheid van die chemiese bedryf in SuidAlrika. Ek wil nou oorgaan tot die rol wat standaardisasie 'n uiters belangrike hulpmiddel - in hierdie bedryf speel.

Die begrip standaardisasie word tog alte dikwels vertolk as synde 'n proses van gelykmaking en dus 'n teenvoeter van vooruitgang en ontwikkeling. Dit is natuurlik 'n totaal verkeerde opvatting.

Dit kan sonder vrees van teenspraak beweer word dat die ontwikkeling van die nywerheidswese van die wetenskap afhanklik is. Meer nog, die suksesvolle voortsetting van die nywerheidswese, die handhawing van sy mededingende posisie in die bedryfsiewe, is uitsluitlik afhanklik van dic toepassing van wetenskaplike beginsels en die gebruikmaking van wetenskaplike hulpmiddels.

Standaardisasie is een van die belangrikste van hierdie hulpmiddels, want 'n mens kan sê dat dit die doel van alle standaarde is om norme daar te stel wat die werk van die menslike gemeenskap vergemaklik.

As daar aan sulke norme voldoen word, is die gevolg, 
sonder uitsondering, nie alleen 'n hoër opbrengs van produkte nie, maar ook die ontuikkeling van 'n tegniese en ekonomiese patroon wat steeds bevorderlik is vir die welvaart van die mens en vir eensgesindheid in menslike verhoudings. Meer spesifiek kan 'n mens sê dat standaardisasie die weg baan tot meer ekonomiese grootskaalse produksie deur die uitskakeling van onnodige verskeidenheid. Dit bevorder altyd die ekonomiese gebruik van arbeid, materiale en werktuie en word dus of ' $n$ instrument tot die verlaging van pryse of 'n magtige remskoen vir die steeds stygende lewenskoste.

Standaardisasie stel 'n land, en veral 'n ontwikkelde land, in staat om die besmoontlike gebruik van sy natuurlike hulpbronne te maak en steeds te vorder tot 'n beter posisie ten opsigte van die handel, sowel buite- as binnelands.

Standaardisasie bevorder ook die gesondheid van nywerheidswerkers en dus die doeltreffende benutting van mensemateriaal. Hieroor kan 'n mens lank gesels veral wat die chemiese bedryf betref, maar ek meen dat dit ons dalk te ver van die eintlike onderwerp af sal voer.

As ons nou die moontlikheid van standaardisasie in die chemiese vervaardigingsbedryf beskou, moet ons erken dat die bedryf hom nie maklik tot die toepassing van standaardisasie leen nie. Dit is natuurlik 'n kapitaal-intensiewe bedryf waar toerusting duur is en uaar sowel toerusting as prosesse baie gou kan verouder en dus dikwels aanpassing verg.

Nog 'n belangrike kenmerk van die chemiese bedryf, maar ook een wat standaardisering bemoeilik, is sy buigsaamheid. 'n Bepaalde chemiese produk kan volgens verskillende prosesse en van verskillende grondstowwe vervaardig word. Etielalkohol byvoorbeeld kan sinteties vervaardig word of dit kan deur die gisting van suiker of stysel verkry word. Die prosesse is totaal verskillend en slegs die eindproduk is dieselfde.

'n Proses kan ook verouderd raak in die proefaanlegstadium nog voordat volskaalse produksie onderneem kan word. Dit gebeur as gevolg van navorsing in die laboratorium, wat steeds die ontwerp van meer ekonomiese of veiliger prosesse ten doel het.

Die inherente diversiteit van die nywerheid loop deur na vervaardigingsfasiliteite: 'n vervaardiger kan byvoorbeeld ' $n$ petroleumaanleg redelik gou en maklik omskep tot 'n aanleg wat tussenprodukte vir die vervaardiging van plastiek- en reinigingsmiddels vervaardig. 
Dit is dus duidelik dat ons met 'n baie komplekse bedryf te doen het en dat sy aard dit moeilik maak om te standaardiseer ten opsigte van toerusting, prosesse of eindprodukte. Hierdie probleme is egter nie genoegsame rede waarom 'n ernstige poging om te standaardiseer nie binne die bedryf aangewend moet word nie.

Ek wil graag 'n paar aspekte van die chemie en die chemiese bedryf noem waar standaardisasie wel toegepas kan word, naamlik nomenklatuur, toetsmetodes, grondstowwe en eindprodukte.

Sedert die vroegste beskawing het die mens dit nodig ge vind om metodes van standaardisasie te gebruik: hy het byvoorbeeld 'n sisteem ontwerp vir die terminologie van verskeie materiale waarmee hy vertroud was. So het goud, wat nog altyd as die edelste van alle metale beskou word, in die ideografie dieselfde simbool ontvang as die son, wat van alle natuurverskynsels die hoogste geëer is omdat dit 'n noodsaaklikheid vir alle lewe op aarde is. So ook het silver die simbool van Venus gedra. Later is 'n sisteem van lettersimbole ontwikkel en uiteindelik is ' $n$ reeks standaardsimbole in gebruik geneem vir alle bekende chemiese elemente en samestellings. Hierdie vroeëre standaardisasie was 'n absolute vereiste vir die ontwikkeling van die chemie en die chemiese nywerheid en hierdie simbole word natuurlik vandag universeel gebruik.

Die struktuurformule in die chemie deel presiese en ondubbelsinnige inligting mee ten opsigte van die struktuur van 'n chemiese stof, maar 'n effektiewe stelsel van nomenklatuur is 'n basiese vereiste vir die oorsetting van sulke formules in woorde.

Sedert die oorspronklike poging deur Bergman in 1770 was daar indiwiduele en nasionale pogings om nomenklatuur te sistematiseer. Veel later eers, naamlik in 1892, is die eerste internasionale konferensie in Genève gehou om hierdie probleem te probeer oplos, maar dit was nie geslaagd nie. Die verslag van die Kommissie vir die Hervorming van Nomenklatuur in Organiese Chemie van die Internasionale Unie vir Chemie is eers in 1930 gepubliseer, en verdere uitbreidings en hersienings van die nomenklatuurreëls vir organiese chemie is deur die International Union of Pure and Applied Chemistry in 1947 bekragtig.

Gedurende die afgelope dekade is baie werk gedoen om 
terminologie in verskeie chemiese gebiedsvelde en nywerhede te standaardiseer, omdat terminologie 'n fundamentele norm is waarsonder standaarde en spesifikasies nie opgestel kan word nie.

Ek wil graag twee van hierclie aktiwiteite noem.

Die Tegniese Komitee, $\mathrm{nr}$. 91 van die Internasionale Standaarde-organisasie, poog om oppervlak-aktiewe middele (surface active agents) te klassifiseer in die vorm van 'n desimale notering, sodat 'n duidelike en ordelike designasie van die strukturele chemiese groepe voorsien kan word.

Verder is die Tegniese Komitee, nr. 81 van die Internasionale Standaarde-organisasie, besig met die opstel van 'n eenvormige naamlys vir plaasbestrydingsmiddels. Dit is uiters belangrik dat standaardisasie hier toegepas word en dat eenvormige name dwarsdeur die wêreld erken word, veral uit 'n gesondheidsoogpunt, gesien die groot gevaar wat giftige chemiese reste wat op vrugte en groente voorkom vir die mens inhou.

Ek vertrou dat ek $\mathbf{u}$ oortuig het van die waarde van standaardisasie van nomenklatuur. Ons moet nou kyk na die waarde van standaardtoetsmetodes.

Daar was 'n tyd toe baie verbruikersprodukte deur die indiwiduele vakman vervaardig is en sy integriteit en sy vaardigheid die waarborg van gehalte was. Maar vandat massaproduksie aan die orde van die dag is, het dit nodig geword om kontroletoetse op fabrieksprodukte in te stel.

Ek wil twee hooftipes toetse noem, naamlik standaard of presiese metodes en empiriese metodes.

In albei gevalle is dit 'n voorvereiste dat uit ervaring bewys moet word dat die toetse behoubaar is, dat hulle akkuraat is, dat hulle herhaalbare resultate lewer, dat hulle deur verskillende ontleedkundiges wat in verskillende laboratoriums werk, sonder moeite of aanpassings toegepas kan word, en dat hulle die kortste moontlike metodes volg.

Die presiese metode moet kan aandui wat die juiste samestelling of werklike inhoud van die bepaalde stof of materiaal is, of die werklike inhoud van een of ander bestanddeel.

Om 'n eenvoudige voorbeeld te noem: as ons byvoorbeeld fyn tafelsout ontleed dan moet ons presies kan bepaal wat die graad of suiwerheid is, en hoeveel ongewenste of moontlik skadelike bestanddele teenwoordig mag wees. Wanneer ons by farmaseutiese produkte kom, is die voorskrif te veel strenger 
en moet ons tot 'n deel van 'n duisendste van 'n persent kan bepaal hoe suiwer die stof is, want hier gaan dit om die mens se gesondheid en die moontlike teenwoordigheid van giftige of skadelike stowwe wat in minimale hoeveelhede skadelik mag wees. Vir hierdie tipe ontleding bestaan daar in die meeste gevalle erkende internasionale standaardmetodes waarvan nie afgewyk durf word nie tensy hulle deur nuwe of verbeterde metodes vervang word wat ook weer deur internasionale ooreenkoms bepaal word.

Die tweede groep metodes wat ek genoem het is die empiriese of vergelykende metodes van ontleding of waardebepaling. In hierdie geval word geen presiese resultate behaal nie, maar tog word die werkverrigting of eienskappe van 'n produk op vergelykende grondslag bepaal.

Ek kan hier noem: die verskillende versnelde metodes vir die toets van verf en verfprodukte en metodes vir die bepaling van die relatiewe lewensduur van hierdie produkte; dan is daar die soutspreitoetse om korrosie van metale en ander stowwe te bepaal; toetse vir die kleurvastheid van tekstielprodukte; en metodes om die weerstand teen hael van verskillende dakmateriale te bepaal. So kan 'n mens nog honderde ander versnelde of vergelykende toetse noem. Ook in die geval van hierdie empiriese toetse is dit noodsaaklik dat nasionale ooreenkoms bereik word, en daarna internasionale ooreenkoms. Daar is sekere internasionale liggame wat hulle hierop toelê, want wat hierdie tipe toetsmetodes betref is dit absoluut noodsaaklik vir die chemiese bedryf om sover moontlik te standaardiseer.

Maar wat toetsmetodes betref lei standaardisering ons na ' $n$ beskouing van moontlikhede in die standaardisasie van grondstowwe en eindprodukte.

Die eindproduk van een chemiese proses vorm dikwels die grondstof vir 'n volgende proses of bedryf, sodat die standaardisasie van grondstowwe en eindprodukte dikwels inmekaar loop. Standaardisasie in hierdie geval mag heel eenvoudig wees en beperk wees tot byvoorbeeld die grootte van mineraaldele, of dit kan veel meer omvattend wees en die samestelling van 'n legering of 'n vloeibare mengsel of ander produk bepaal. Standaarde word in hierdie gevalle gewoonlik op ooreenkoms tussen leweransier en verbruiker gebaseer en raak dikwels niemand anders nie. Dit is nietemin ' $n$ baie be- 
langrike aspek waaraan chemiese vervaardigers behoorlik aandag moet skenk.

Standaardisasie van die eindproduk kan beperk wees tot die samestelling van 'n enkele produk of chemiese stof soos 'n koperstaaf, of tot saamgestelde produkte soos verf, seep, reinigingsmiddels, voedselprodukte, en so meer.

Standaardisasie word hier van wesentlike belang, omdat dit in alle gevalle vereenvoudiging meebring wat tot reëlmaat in die nywerheid lei, produksiekoste verlaag en prysdaling van produkte tot gevolg het.

Kom ons neem die geval van verf, waar in die afgelope paar jaar 20 nasionale standaarde opgestel is om alle tipes verf te dek. Ek sal liewer nie wil bereken hoeveel tipes voorheen bestaan het en tot hoeveel verwarring dit gelei het nie. Om die punt te staaf dat standaardisasie tot prysclalings lei, kan ek noem dat die prys van 'n sekere tipe verf wat deur die Staat aangekoop word gedaal het van R2.80 per gelling tot R1.50 per gelling toe dit teen 'n standaardspesifikasie vervaardig is. Die gemiddelde prys waarteen die Staat verf aankoop het gedaal van R3 tot R2 per gelling. Standaardverfsoorte is vandag verkrygbaar, en dit is die publiek se plig in eie belang om aan te dring op standaardprodukte; dan sal hulle ook mettertyd die voordeel van die prysdalings ervaar.

Verf is egter nie die enigste produk waar standaardisasie tot voordeel toegepas is nie. Ek kan vir u noem dat 80 tipes en grade olie en smeermiddels wat deur die Staat aangekoop word deur standaardisasie verminder is tot 10 basiese tipes met 'n gemiddelde prysdaling van 25 persent. Ek kan vir u die geval noem van seep waarvan die prys na die toepassing van nasionale standaarde, gedaal het van R7 per 100 pond tot R4.40 per 100 pond.

Daar is reeds nasionale standaarde opgestel vir produkte soos reinigingsmiddels, politoer, PVC-produkte, poliëtileenprodukte, witmetale, soldeersel, smeermiddels en brandstowwe, bitumineuse materiale en asfalt, rubberprodukte, sout, eter vir verskillende toepassings, sement, keramiese produkte, insekdodende middels, kalk, ink, skoolkryt, en nog baie ander. Standaardisasie het in al hierdie gevalle leiding aan die vervaardiger gegee en hom in staat gestel om groter hosveelheds. van 'n kleiner reeks produkte te vervaardig en wel tot bevrediging van die verbruiker, en dit het in die algemeen tot groot reëlmaat in die bedryf gelei. 
In baie gevalle word van internasionale standaarde gebruik gemaak, of dan van Britse, Duitse of Amerikaanse standaarde, wat in wye kringe bekend en aanvaarbaar is. Ons hoef nie chauvinisties te wees en altyd daarop aan te dring dat produkte aan 'n Suid-Afrikaanse standaard moet beantwoord nie. Ons moet net insien dat dit uiters belangrik is dat die beginsel van standaardisasie in die chemiese bedryf toegepas word.

\section{Gedagtes oor die toekoms}

Daar kan nog veel gedoen word om standaardisasie in die chemiese bedryf te bevorder, nie alleen binne maatskappye nie, maar ook op nasionale basis. Ek dink veral aan die ontwikkeling van standaarde vir nywerheidsgrondstouwe en primêre produkte.

Ek hoop ek het daarin geslaag om vir $u$ aan te dui hoe belangrik standaarde in die chemiese bedryf is. Die ekonomiese en rigtinggewende voordele daarvan in die algemeen is onlangs op die hoogste vlak in ons land erken, nl. deur die Kabinet op aanbeveling van die Ekonomiese Adviesraad van die Eerste Minister. Opdrag is gegee om alle staatsaankope te koördineer en te standaardiseer, en dit word gedoen. Die georganiseerde nywerheid, die handel, die mynwese en verbruikersliggame het ook die beginsel aanvaar; nietemin is daar nog die gaping tussen lippediens en werklike toepassing, en hier verwys ek na die nywerheid wat nog veel meer kan doen. Die gedagte moet in die nywerheid ingedra word deur die jongmense wat ons nou oplei om die nywerheid te kan dien. Ons praat vanaand spesifiek oor die chemiese bedryf, en my pleidooi is dan dat die studente in die Departement Industriële Chemie werklik bewus gemaak moet word van die kostestruktuur in 'n nywerheid, want alleen as dit verstaan word sal hulle hul beywer om produkte te lewer wat kompeterend op die tuis- en buitelandse mark sal wees.

Die pogings om die koste in die nywerheid laag te hou, begin by die ontwerp van die masjien en loop deur na die beplanning van die proses, die gehaltebeheer tydens produksie, en die toets en sertifisering van die eindproduk. Standaardisasie speel in al hierdie gevalle 'n groot rol. Daar is dus interessante werk om te doen.

Hierdie gedagtes oor die toekoms van ons chemiese nywerheid wil ek graag laat posvat by die jongmense vanaand teenuroordig.

Pretoria.

A. W. Lategan. 